\section{Clinicians should consider the effect of bodily metaphors when discussing contraceptive options}

The way in which women imagine their own bodies, and the metaphors upon which they draw, may affect their attitudes towards and willingness to use certain methods of contraception. Biomedical science draws upon an implicitly mechanistic metaphor, which views the human body as a complex machine with purely utilitarian functions. ${ }^{1}$ This metaphor is reflected in medical education, clinical discourse and in patient information resources. I have published a research article which suggests that a minority of women, who access contraceptive services, may draw upon an alternative 'natural' bodily metaphor, which views the body as an entity firmly embedded in the wider ecology, with quasi-spiritual status, whose functions ought not to be disrupted by technological interventions. ${ }^{2}$ The disruption to the menstrual cycle, and other bodily rhythms, caused by hormonal methods of contraception, provoked particular anxiety for women who drew upon this bodily metaphor, to the extent that they often discontinued hormonal methods. It seems likely that clinical conversations and negotiations about contraception, in which two dissonant metaphors of the body are invoked (i.e. utilitarian/mechanistic vs spiritual/natural), will cause disagreement around the risks, benefits and suitability of a particular method. It also seems likely that advice about less effective, but more acceptable, 'natural' methods of contraception (such as withdrawal or natural family planning) will provide more reliable fertility control for women who are uneasy about methods that are more technologically interventionist. In my paper $^{2}$ I suggest that clinicians should be alert to alternative understandings of the body, which may influence the acceptability of commonly prescribed methods.

Susan Walker, DFSRH, PhD

Senior Lecturer in Sexual Health, Department of Primary and Public Health, Faculty of Health, Social Care and Education, Anglia Ruskin University, Chelmsford, UK; susan.walker@anglia.ac.uk

Competing interests None.

Journal of Family Planning and Reproductive Health Care 2013;39:152. doi:10.1136/jfprhc-2012-100561

\section{REFERENCES}

1 Turner BS. Medical Power and Social Knowledge (2nd edn). London, UK: Sage, 1995;4-10.

2 Walker SH. Mechanistic and "natural" body metaphors and their effects on attitudes to hormonal contraception. Women Health 2012;52:788-803. 